Asian J. Med. Biol. Res. 2019, 5 (4), 336-342; doi: 10.3329/ajmbr.v5i4.45273

\author{
Asian Journal of \\ Medical and Biological Research \\ ISSN 2411-4472 (Print) 2412-5571 (Online) \\ www.ebupress.com/journal/ajmbr
}

\title{
Article \\ Isolation of bacterial flora from post burn infection: influence of socio- demographic background on the occurrence of burn injury
}

\author{
Amatun Nasir Tama ${ }^{1 *}$, Aleya Begum ${ }^{1}$, Mandira Mukutmoni ${ }^{1}$ and Mohammad Rabiul Karim Khan $^{2}$ \\ ${ }^{1}$ Department of Zoology, University of Dhaka, Dhaka 1000, Bangladesh \\ ${ }^{2}$ National Institute of Burn and Plastic Surgery, Dhaka Medical College, Bangladesh
}

*Corresponding author: Amatun Nasir Tama, Department of Zoology, University of Dhaka, Bangladesh. Email: ratri89.du@live.com

Received: 17 November 2019/Accepted: 23 December 2019/ Published: 31 December 2019

\begin{abstract}
The objective of this work was to find out the bacteriological profile and risk factor for burn patients. Sixty burn patients were investigated during July 2014 to May 2015. Specimens were collected in the form of wound swabs. The prospective study showed that one third of the patients below 10 years old belong the highest burn infections. The rate of burn infections was higher (61.67\%) in female compared to male patients. Respondents under primary level were the major victims $(28.33 \%)$. On the basis of occupational status, student showed the highest (30\%) infection. Maximum (48.33\%) patients were injured by first degree burn. Hot liquids (scald) was found as one of the main causes of burn which was $50 \%$ prevalent. Forensic background explained maximum burn injuries were accidental (88.34\%). Most of the children were the main victims during playing (36.67\%) followed by working persons (25\%). Pseudomonas spp (73\%) was found to be the most common isolated microorganisms followed by Klebsiella spp (6.67\%), Staphylococcus aureus (6.67\%), Escherichia coli (6.67\%), Proteus spp (5\%) and Enterobacter (1. 6\%). Some medical devices like floor, bed, water etc. were detected as positive sources of organisms. By antibiotic susceptibility tests it was found that Pseudomonas are resistant to ceftriaxone (100\%) followed by ceftazidime (93\%) and sensitive to colistin (90\%). In the case of Staphylococcus aureus, $100 \%$ are resistant to amoxyclave and $100 \%$ are sensitive to ciprofloxacin.
\end{abstract}

Keywords: burn; socio-demographic background; bacteria; antibiotic

\section{Introduction}

Burn injuries constitute a severe emotive, psychosomatic and societal crisis for the affected individuals and their families. It has been estimated that about $75 \%$ of the mortality associated with burn injuries is related to sepsis especially in developing countries (Donati et al., 1993). They can be caused by scalds, thermal, electrical, gas or chemical agents (Mirmohammadi et al., 2013). Burns account for $1 \%$ of the global burden of diseases and cause more than 7.1 million injuries, a loss of almost 18 million disability-adjusted life years (DALYs), and more than 265,000 deaths worldwide annually (Elsous et al., 2016). Almost 173,000 children in Bangladesh suffered from burn injuries in 2003, making it the 5th leading cause of childhood illness in the country (Mashreky et al., 2008).

Pseudomonas sp, Acinetobacter sp., Proteus mirabillis, Klebsiella sp., Citrobacter sp, Enterobacter sp and Escherichia coli are most common gram negative bacteria associated with burn wounds (Patil et al., 2015). Patients with serious burn injury require immediate specialized care in order to minimize bacterial infection, which is a major cause of morbidity and mortality in burn patients (Rao et al., 2014).

The present study was conducted to determine the bacterial profile of burn wounds, the antimicrobial susceptibility patterns with respect to the source of wound and socio-demographic background of burn injured patients admitted at the National Institute of Burn and Plastic Surgery, Dhaka Medical College Hospital. The 
subsequent information may be employed with the aim of burn wound management to lessen the onset and density of bacterial growth and proliferation within the wounds.

\section{Materials and Methods}

\subsection{Study population}

This study included sixty patients who were admitted to the National Institute of Burn and Plastic Surgery, Dhaka Medical College and Hospital during July 2014 to June 2015 suffering from types of acute burn injuries.

\subsection{Sampling}

Patients with significant major co-morbid medical conditions, psychiatric disorder, poor morale, severe immune compromised and short life expectancy, unwilling to take part in the study, burn wound with history of application of cow dung, toothpaste, egg etc. were excluded from the study. Wound samples were aseptically collected on day of occurrence (day 1), 5 th post burn day and $15^{\text {th }}$ post burn day. Surface swabs were collected from burn wounds after the removal of dressings and topical antimicrobial agents and cleansing of the wound surface with $70 \%$ alcohol (Church et al., 2006). An area of about $4 \mathrm{~cm}^{2}$ will be swabbed using two sterile cotton swabs. Swab samples were collected from the wound area where the degree of burn was the maximum. Samples were homogenized in $4 \mathrm{~mL}$ sterile saline (Alam et al., 2014).

\subsection{Microbiological and biochemical examination}

A complete laboratory examination conducted by Alam et al. (2014) was followed in the present study. Samples were cultured on blood agar and MacConkey agar plates. Pathogenic microorganisms were isolated and identified following the standard procedures (Forbes et al., 1998). MacConkey agar was used for the isolation of Gram negative bacteria while the blood agar was used for isolation and identification of Gram positive bacteria. Nutrient agar was used for the general cultivation and maintenance of bacteria. After inoculation, plates were kept at $37^{\circ} \mathrm{C}$ for $24-48$ hours A series of several biochemical tests were performed following the standard protocol to identify the bacteria isolated from the wound samples (Cappuccino and Sherman 1996).

\subsection{Study of antibiotic susceptibility}

The standard agar disc diffusion method known as the Kirby-Bauer method was applied (Alam et al. 2014; Munshi et al. 2012; Mehta et al. 2007; Bauer et al. 1966). A suspension of the test organisms was prepared by adjusting the turbidity of the broth in phosphate buffer saline by comparing with McFarland 0.5 solutions. Constant lawn of bacterial growth was prepared on Muller Hinton agar plates. Beforehand inoculation, the swab was passed against the wall of the tube to drain out the additional fluid. Commercially accessible antimicrobial discs (Oxoid, Hampshire, UK) were used aseptically on the surface of the inoculated plates at proper spatial plan by means of a sterile needle. Susceptibility to the specific antibiotic was interpreted by the presence of clear zone around the disc (Ferraro et al. 2001).

\section{Results and Discussion}

\subsection{Socio-demographic background and occurrence of burn injury}

The present study demonstrates that the percentage of burn infection in patients aged below 10 years was higher (33.33\%) than the other age groups (Table 1). Out of sixty patients, 20 were in Group I (0-10years), some of whom were school going children. Children are naturally curious, impulsive and active so they can be victim of burn easily. This result correlates with the findings reported by Al-Akayleh (1998) which showed that the age group $<10$ years had the highest distribution of burn wound infection. Group II (11-20 years) comprising 13 patients, both boys and girls, two boys were caught in fire during playing at the street, rest of the boys and girls were found to perform household chores such as cooking and babysitting in the absence of their parents. The authors interviewed 12 patients of Group III (21-30 years) in which most of them were house wives. They were burnt due to flammable substances which were stored in the home and flammable clothing like georgette or linen etc. Authors found five patients in Group IV (31-40 years) who were injured in their working places either by electric voltage or chemicals. Sivamuthu (2019) observed the average age of the burns patient in his study was 32 years and 30-40 years' age group was the most commonly affected. In Group V (41-50 years) and Group VI (51-60 years) we found four patients who got burn injures because of accidental cases.

In South East Asia; young age, female gender, poor socio-economic status and low educational level are identified as major risk factors for burn related injuries and death (Wolf and Arnoldo, 2012). In the present study, percentage of burn injuries were higher in female (61.67\%) than in the male (38.33\%) (Table 1). This correlates well with Goswami et al. (2016) but differs with Othman and Kendrick (2010) where male case more 
commonly involved. In Bangladesh, traditional dress is sharee or salwar- kamiz or kurta through which fire are spread quickly. A woman usually spends a big time in kitchen where the sources of fire are present. Unfortunately, females are the main victim of acid burning too. The present study found eight female patients who were attacked by their husbands' family for dowry. Authors studied three other cases which were also homicidal in which patients were injured by "petrol bomb" at the time of political violence in Bangladesh.

In the present study, males were found to be injured accidentally at home or at their working places. At the construction sites in developing countries, it is allowed to do electrical works without protection, which is a major cause of burn injury. Despite significant improvements in product safety, electrical injury is still the cause of many fatalities and of considerable morbidity in developed countries (Koumbourlis, 2002). In the present study, occurrence of burn injury was higher among the patients educated under primary level $(28.33 \%)$ followed by primary level (23. 33\%). Among the graduate and above (6.67\%), burn injury was the lowest (Figure 1). Low literacy and a lack of safety measures when in dealings with electricity and other sources might be the reason behind high burn occurrence among the poorly educated. Among the 60 patients, 25(41.67\%) were students which was the maximum. The lowest rate of burn injury was observed among farmers $(6.67 \%)$ (Table $1)$.

\subsection{Cause and degree of burn injury}

In the present study, 1-10\% burn showed the highest occurrence (41.67\%). Above 30\% burn displayed the lowest occurrence (Table 2). Out of 60 respondents, most were injured by scald (29), followed by flame (13), electric (11), chemical (7). Forson et al. (2017) found 33(66\%) of the studied patients had flame injury caused by gas, while $14(28 \%)$ had scald injury and $3(6 \%)$ had electrical injuries. This correlates with a study conducted by Shahzad et al. (2012) in Pakistan, which reported the predominant burn agent to be gas flame $(76 \%)$, followed by scald $(14 \%)$, contact $(6 \%)$, electrical $(3 \%)$ and chemical $(1 \%)$. Furthermore, the study reveals that most of the cases were accidental (88.33\%) followed by suicidal (6.67\%) and homicidal (5\%) (Table 3). Sivamuthu (2019) found that etiologies of injuries were flame burns (60\%), scalds (25\%), electrical burns $(10 \%)$ and chemical burns (5\%). Most of the burn injuries in his study were accidental (65\%), followed by suicidal (15\%), industrial (12\%) and homicidal (8\%). In the present study, $36.67 \%$ children were playing at the time of injury. $25 \%$ patients were injured during working followed by $13.33 \%$ patients who were involved in cooking, bathing with hot water (13.33\%) and other works $(8.33 \%)$ while burning (Table 3 ). The study reveals that $66.67 \%$ injuries occurred at home and surrounding areas followed by construction area $(25 \%)$ and street (8.33\%) (Table 3).

\subsection{Sources of organism}

Samples were collected from trolley used for patients but no growth of organisms was found. The floor of emergency and ward were also checked. After $5 \mathrm{pm}$, growth of organisms from floor was notified as it was the last time for weeping the floor with disinfectants. Authors found growth of organisms at the bed of patients (Table 4). Bed covers were not regularly changed. Patient housing in single bed in a room with a separate sink facility to wash hands and change in staffing pattern has been shown to prevent infection and reduce mortality (Shirani et al., 1986). Authors checked the curtain of emergency, cotton used for dressing, plaster, silcream, gloves, stethoscope; hand of surgeon, ward boy and nurse before attending patients but found no growth of organisms. Patients body seemed as major source of infection in the present study. The floor and bed of OT complex were found to be free from any growth of organisms because OT complex is a highly protective area (Table 4).

\subsection{Antibiotic sensitivity and resistance}

Usually fresh burn wound are sterile. But with the passing of time it would be infected. We took sample from patients at the $1^{\text {st }}$ day of the incident and cultured but found no growth of organisms. At the $5^{\text {th }}$ day of admission we took sample from each patient and then we found types of bacterial growth in wound. Out of 60 samples we found Pseudomonas sp. in 44 samples (73.33\%) which is a gram negative bacteria followed S. aureus (6.67\%), E. coli (6.67\%), Klebsiella sp. (6.67\%) Proteus sp. (6.67\%) and Enterobacter sp. (1.67\%). Deshpande et al. (2012) found Klebsiella was the most common organism isolated from the culture studies followed by Pseudomonas and methicillin resistant Staphylococcus aureus. Al-Aali (2016) found that the bacterial infection at least once reached $100 \%$ by the end of the 4th week of admission. In his study, S. aureus, Klebsiella pneumoniae and coagulase negative Staphylococci were the most frequently isolated organisms (20.2\%) followed by Pseudomonas aeruginosa (14.6\%) and E. coli (10.1\%) (Table 5). 
In the present study, we found that after taking antibiotics the growth of bacterial flora was decreased. At $15^{\text {th }}$ post burn day we found no growth of bacteria in 38 samples $(63.33 \%)$, rest 12 isolates were Pseudomonas sp. (20\%), followed by S. aureus (5\%), E. coli (3.33\%), Klebsiella sp. (3.33\%) and Proteus sp. (3.33\%) ( $\mathrm{P}=0.035)$ (Table 5). Taneja et al. (2013) observed that colonization rates were 33\% on first day, $94 \%$ on 7 th day and $100 \%$ by 14 th day. $42 \%$ swabs grew gram negative bacteria. Overall Staphylococcus aureus was the predominant isolate (45\%) followed by Pseudomonas aeruginosa (13.9\%).

In case of Pseudomonas sp. 100\% were found resistant to ceftriaxone followed by ceftazidime (93\%) and doxycycline (86.36\%) (Figure 2). 90\% Pseudomonas were found sensitive to colistin followed by imipenin (84.1\%) and are sensitive to piperacillin (88.63\%). S. aureus were resistant to amoxyclave and sensitive to ciprofloxacin (100\%). In case of E. coli, $83.3 \%$ were resistant to piperacillin (Figure 2). In a study conducted by Forson et al. (2017), most of the Pseudomonas sp. were resistant to ampicillin, cotrimoxazole, cefuroxime and ceftriaxone. Whilst most of the Proteus mirabillis were resistant to ampicillin, cotrimoxazole, gentamicin, cefuroxime and ceftriaxone. Klebsiella sp. and Klebsiella oxytoca were both found to be resistant to ampicillin, tetracyclin, cotrimoxazole and ciprofloxacin (Figure 2).

Table 1. Occurrence of burn injury based on socio-demographic background.

\begin{tabular}{lll}
\hline & No. of patients & Prevalence $\mathbf{( \% )}$ \\
\hline Gender & 23 & \\
\hline Male & 37 & 38.83 \\
\hline Female & & 61.67 \\
\hline Age Group & 20 & 33.33 \\
\hline Group I & 18 & 30 \\
\hline Group II & 13 & 21.67 \\
\hline Group III & 5 & 8.33 \\
\hline Group IV & 2 & 3.33 \\
\hline Group V & 2 & 3.33 \\
\hline Group VI & & \\
\hline Profession & 5 & 8.33 \\
\hline Business & 10 & 16.67 \\
\hline Service & 9 & 15 \\
\hline Day laborer & 4 & 6.67 \\
\hline Farmer & 18 & 30 \\
\hline Student & 8 & 13.33 \\
\hline House wife & & \\
\hline \multicolumn{1}{c}{ Other } & 6 & 10 \\
\hline
\end{tabular}

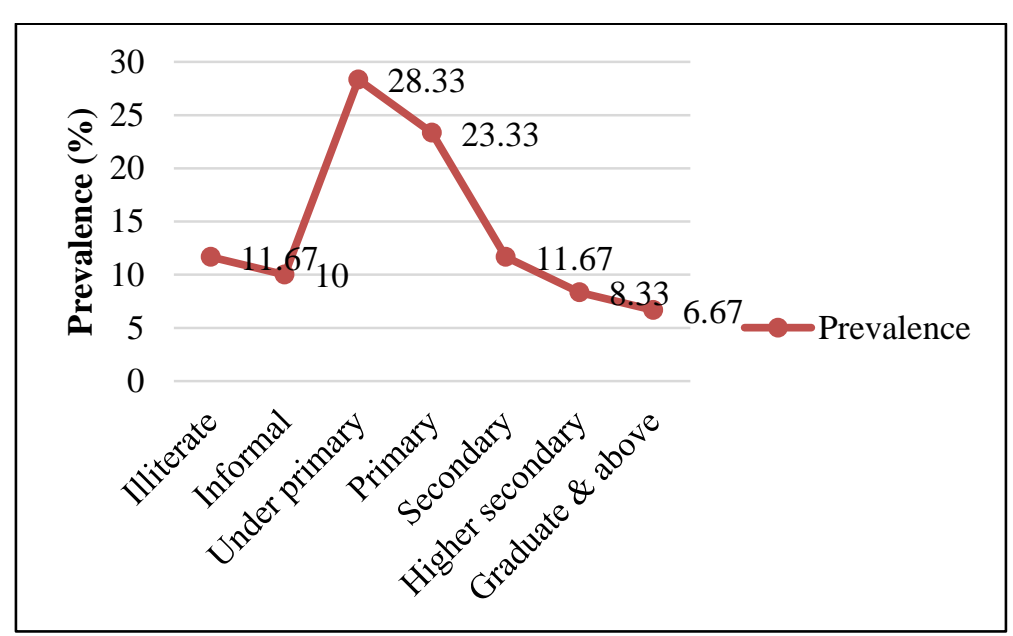

Figure 1. Burn injury and level of literacy. 
Table 2. Degree of burn injury.

\begin{tabular}{llll}
\hline Group & Percentage of burn & No. of patients & Prevalence (\%) \\
\hline I & $01-10 \%$ & 29 & 48.33 \\
\hline II & $11-20 \%$ & 16 & 26.67 \\
\hline III & $21-30 \%$ & 11 & 18.33 \\
\hline IV & $31-40 \%$ & 2 & 3.33 \\
\hline V & $41-50 \%$ & 2 & 3.33 \\
\hline
\end{tabular}

Table 3. Background of burn injury.

\begin{tabular}{lll}
\hline & No. of patients & Percentage (\%) \\
\hline Cause of burn & & \\
\hline Scald & 30 & 50 \\
\hline Flame & 10 & 16.67 \\
\hline Electric & 9 & 15 \\
\hline Chemical & 8 & 13.33 \\
\hline Others & 3 & 5 \\
\hline Forensic background & & \\
\hline Accidental & 53 & 88.34 \\
\hline Suicidal & 2 & 3.33 \\
\hline Homicidal & 5 & 8.33 \\
\hline Place & & \\
\hline Construction area & 12 & 20 \\
\hline Kitchen & 17 & 28.33 \\
\hline Bathroom & 6 & 10 \\
\hline Other places in home & 18 & 30 \\
\hline Street & 2 & 3.33 \\
\hline Others & 5 & 8.34 \\
\hline Activity & & \\
\hline Working & 15 & 25 \\
\hline Cooking & 9 & 15 \\
\hline Playing & 22 & 36.67 \\
\hline Bathing & 8 & 13.33 \\
\hline Others & 6 & 10 \\
\hline
\end{tabular}

Table 4. Source of organisms.

\begin{tabular}{lll}
\hline Medical devices & \multicolumn{2}{l}{ Growth of microorganisms } \\
\hline Trolley & Yes & No \\
\hline Floor(Emergency) & $\sqrt{ }$ & $\sqrt{ }$ \\
\hline Floor( Ward) & $\sqrt{ }$ & \\
\hline Bed & $\sqrt{ }$ & $\sqrt{ }$ \\
\hline Curtain & & $\sqrt{ }$ \\
\hline Cotton used for dressing & & $\sqrt{ }$ \\
\hline Plaster & & $\sqrt{ }$ \\
\hline Silcream & & $\sqrt{ }$ \\
\hline Gloves & & $\sqrt{ }$ \\
\hline Stethoscope & & \\
\hline Hand of ward boy & $\sqrt{ }$ \\
\hline Patient body & & $\sqrt{ }$ \\
\hline Hand of surgeon & & $\sqrt{ }$ \\
\hline Hand of Nurse & & \\
\hline OT complex & & \\
\hline
\end{tabular}


Table 5. Bacterial flora in burn wound.

\begin{tabular}{|c|c|c|c|c|c|c|c|c|c|c|c|c|c|c|}
\hline \multirow[t]{2}{*}{ Day } & \multicolumn{2}{|c|}{$\begin{array}{l}\text { Pseudomonas } \\
\text { sp. }\end{array}$} & \multicolumn{2}{|c|}{ S. aureus } & \multicolumn{2}{|c|}{ E. coli } & \multicolumn{2}{|c|}{$\begin{array}{l}\text { Klebsiella } \\
\text { sp. }\end{array}$} & \multicolumn{2}{|c|}{ Proteus sp. } & \multicolumn{2}{|c|}{ Others } & \multicolumn{2}{|c|}{ Absent } \\
\hline & + & $\%$ & + & $\%$ & + & $\%$ & + & $\%$ & + & $\%$ & + & $\%$ & + & $\%$ \\
\hline $5^{\text {th }}$ & 44 & 73.33 & 4 & 6.67 & 4 & 6.67 & 4 & 6.67 & 3 & 5 & 1 & 1.67 & 0 & 0 \\
\hline $15^{\text {th }}$ & 12 & 20 & 3 & 5 & 2 & 3.33 & 2 & 3.33 & 2 & 3.33 & 1 & 1.67 & 38 & 63.33 \\
\hline
\end{tabular}

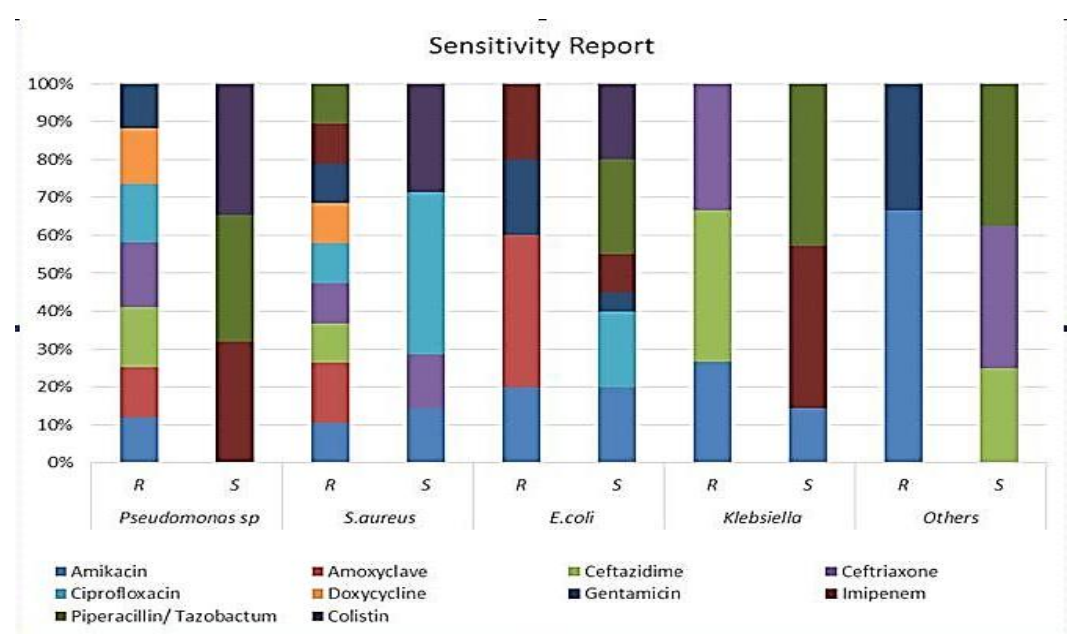

Figure 2. Antibiotic sensitivity.

\section{Conclusions}

Burns provide a suitable site for bacterial growth and contamination, mainly because of the greater area involved and lengthier period of patient stay in the hospital. To ensure early and appropriate therapy in burn patients, a frequent evaluation of the wound is necessary, a strict antibiotic policy should be followed by all burn institutions and a rotation program for topical antimicrobial may retard the development of resistance Mass education and household environmental adjustment should be considered to prevent burn injury and infection. Special attention should be given to handle unsafe fire and other injury sources.

\section{Conflict of interest}

None to declare.

\section{References}

AL-Aali KY, 2016. Microbial profile of burn wound infections in burn patients, Taif, Saudi Arabia. Arch Clin. Microbiol., 7.

Al-Akayleh AT, 1999. Invasive burn wound infection. Ann. Burns. Fire Disasters., 7: 1-3.

Bauer AW, WM Kirby, JC Sherris and M Tierch, 1966. Antibiotic susceptibility testing by a standardized single disc method. Am. J. Clin. Pathol., 45: 493-496.

Cappuccino JG and N Sherman, 1996. Microbiology-a laboratory manual. $4^{\text {th }}$ ed. California: Benjamin/Cummings Pub. Co. 477 pp.

Church D, S Elsayed, O Reid, B Winston and R Lindsay, 2006. Burn wound infections. Clin. Microbiol. Rev. 19: 403-434.

Deshpande JD, PK Baviskar and DB Phalke, 2012. Epidemiological study of hospitalized burn patients in rural area. Inter. J. Biomed. Advanced Res., 3: 263-7.

Donati L, F Scammazo, M Gervasoni, A Magliano and B Stankow, 1993. Infection and antibiotic therapy in 4000 burned patients in Milani Italy between 1976 and 1988. Burns, 4: 345-348.

Elsous A, M Ouda, S Mohsen, M Al-Shaikh, S Mokayad and N Abo-Shaban, 2016. Epidemiology and outcomes of hospitalized burn patients in Gaza Strip: a descriptive study. Ethiopian J. Health Sci., 26: 9-16.

Ferraro MJ, WA Craig, MN Dudley, GM Eliopoulos, DW Hecht and J Hindler, 2001. Performance standards for antimicrobial disk susceptibility testing. Wayne, USA: National Committee for Clinical Laboratory Standards. 
Forbes BA, DF Sahm, AS Weissfeld and EJ Baron, 1998. Bailley \& Scott's diagnostic microbiology. 10th ed. St Louis: Mosby Inc.

Forson OA, E Ayanka, M Olu-Taiwo, PJ Pappoe-Ashong, and PJ Ayeh-Kumi, 2017. Bacterial infections in burn wound patients at a tertiary teaching hospital in Accra, Ghana. Ann. Burns. Fire Disasters, 30: 116-120.

Goswami P, P Singodia, AK Sinha, T Tudu, 2016. Five-year epidemiological study of burn patients admitted in burns care unit, Tata Main Hospital, Jamshedpur, Jharkhand, India. Ind. J. Burns, 24: 41. 9.

Koumbourlis AC, 2002. Electrical injuries. Crit. Care Med., 30: S424-S430.

Mashreky SR, A Rahman, S Chowdhury, S Giashuddin, L Svanström, M Linnan, S Shafinaz, IJ Uhaa and F Rahman, 2008. Epidemiology of childhood burn: Yield of largest community based injury survey in Bangladesh. Burns, 34: 856-862.

Mehta M, P Dutta and V Gupta, 2007. Bacterial isolates from burn wound infections and their antibiograms: an eight-year study. Indian J. Plast. Surg., 40: 25-28.

Mirmohammadi SJ, AH Mehrparvar, K Kazemeini and M Mostaghaci, 2013. Epidemiology characteristics of occupational burns in Yazd, Iran. Int. J. Prev. Med., 4: 723-727.

Munshi SK, MM Rahman and R Noor, 2012. Detection of virulence potential of diarrheagenic Escherichia coli isolated from surface water of rivers surrounding Dhaka city. J. Bangladesh Acad. Sci., 36: 109-121.

Othman N and D Kendrick, 2010. Epidemiology of burn injuries in the East Mediterranean Region: a systematic review. BMC Public Health, 10: 83.

Patil P, S Joshi and R Bharadwaj, 2015. Aerobic bacterial infections in a burns unit of Sassoon General Hospital, Pune. Int. J. Healthcare. Biomed. Res., 3: 106-112.

Rao SR, LJ Lakshmi, S Pavani, V Kawle and SJ Prakash, 2014. Bacteriological profile, Antibiogram of burn wound isolates and detection of MRSA and ESBL production at tertiary care hospital, Hyderabad. World Journal of Pharmacy and Pharmaceutical Sciences, 3: 1691-1698.

Shahzad MN, N Ahmed, IH Khan and AB Mirza and F Waheed. 2012. Bacterial profile of burn wound infections in burn patients. Ann. Pak. Inst. Med. Sci., 8: 54-57.

Shirani KZ, AT McManus, GM Vaughan, WF McManus, BA Jr Pruitt and AD Jr Mason, 1986. Effects of environment on infection in burn patients. Arch. Surg., 121: 31-36.

Sivamuthu CT, 2019. An epidemiological study of 100 cases of burn injuries. Int. Surg. J., 6: 428-31.

Alam SMS, MA Kalam, MS Munna, SK Munshi and R Noor, 2014. Isolation of pathogenic microorganisms from burn patients admitted in Dhaka Medical College and Hospital and demonstration of their drug resistance traits. Asian Pac. J. Trop. Dis., 4: 402-407.

Taneja N, PS Chari, M Singh, G Singh, M Biswa and M Sharma, 2013. Evolution of bacterial flora in burn wounds: key role of environmental disinfection in control of infection. Int. J. Burn Trauma., 3: 102-107.

Wolf SE and BD Arnoldo, 2012. The year in burns 2011. Burns, 38: 1096-1108. 